\title{
Diversity and uniqueness of Family business in the North of Portugal
}

Ana Paula Marques

Department of Sociology at the University of Minho Interdisciplinary Centre of Social Sciences (UMinho Pole)

\begin{abstract}
Family businesses are the most omnipresent form of business organisations at the international and national levels. In Portugal, family firms account for more than $70 \%$ of all businesses, contributing with $50 \%$ in employment creation. Yet, most of the existing literature does not converge in a consensual and operative definition of what are core elements which distinguish family business from non-family business. Therefore, it is crucial to extend our knowledge on important family business topics due to the broadness, diversity, uniqueness and growth potential of family business in the whole world. In this sense, the ongoing project "Roadmap for Portuguese Family Businesses" (NORTE2020/FEDER) is focused on providing a better understanding and assessment of the impact of family businesses in the North of Portugal on the local, national and international economies. This research addresses a major problem that has been identified in Europe and consists in the lack of institutional visibility, particularly of accurate and up-to-date statistics in this sector. This paper begins by identifying some of the interesting research questions that emerge from examining the business family portraits. Then, based on some preliminary empirical findings gathered from ongoing research, first of all, we intend to identify interesting profiles of family business by mobilising some socioeconomic variables; and secondly, to point out major challenges faced by Portuguese family business.
\end{abstract}

Keywords: Portugal, family business, diversity and uniqueness, challenges and key factors of success

\section{Introduction}

With a long-term vision, family businesses (FB) contribute significantly to GDP and employment, to innovation and the development of local communities, constituting one of the key pillars of the growth of any country's economy. In fact, family businesses constitute the dominant business form, their success and long-term stability being essential to the economy and society. However, one of the major problems family businesses face in Europe and in Portugal is the lack of politicalinstitutional visibility, where there are still no precise official and updated statistics on this sector of the economy. There are only a few estimates that express the importance of this business typology on private economy overall, varying from country to country.

According to the report of the Committee on Industry, Research and Energy, which is under the purview of the European Union, $85 \%$ of all the European companies are family businesses, and these represent $60 \%$ of the jobs in the private sector $^{1}$. In Spain, family businesses represent roughly $75 \%$ of the total number of companies, whereas in Portugal, it is foreseen that family businesses may represent between $70 \%$ and $80 \%$ of the national businesses, taking up $50 \%$ of the workforce and contributing to $2 / 3$ of the GDP2. Expanding to the non-European space, we observe that the relative importance of family businesses is more significant in regions like Australia (70\%), Latin America (between 65\% to 90\%), and the United States of America (between 90 to 95\%) (International Family Enterprise Research Academy [IFERA], 2003). Therefore, it is important to make available current and reliable statistic information on family businesses, whose shortcoming is signalled for the national and European context, as attested by reference documents in which the role of

\footnotetext{
1 Online information: http://www.europarl.europa.eu/oeil/popups/printsummary.pdf?id=1395260\&l=en\&t=D accessed on 4.4.18].

2 Online information: http://www.empresasfamiliares.pt/quem-somos accessed on 4.4.2018]. 
small and medium family enterprises is enshrined as a substantial part of European companies - Small Business Act and of the dynamic performance of the European economy (EC, 2009).

The present article is based on the ongoing project "Roadmap for Portuguese Family-Owned Businesses" (NORTE-020853-FEDER-000018), in co-promotion with the Portuguese Entrepreneurial Association [Associação Empresarial de Portugal (AEP)], and funded by Norte 2020 and FEDER- Fundo Europeu de Desenvolvimento Regional, (European Regional Development Fund). This project pursues a double strategic goal: (1) to map family businesses of the North Region, whether small, medium or large; (2) to assess their impact on local, national and international economy, taking into account the dynamics of job creation, internationalisation and investment innovation, on the one hand and, on the other hand, the professionalisation of the management and governance of family companies. This is a project which aims to map this dominant business typology in the Portuguese economic fabric, characterising and identifying the main challenges and emerging trends. It will generate accurate and reliable statistical data as well as knowledge which could assist political stakeholders in decision-making, securing greater visibility for the issue of family businesses

This paper begins by identifying some of the interesting research questions that emerge from examining the business family portraits. Then, based on some preliminary empirical findings gathered from ongoing research, firstly, we intend to identify interesting profiles of family business by mobilising some socioeconomic variables; and secondly, point out major challenges faced by Portuguese family business.

\section{Singularities of family business}

The family businesses are cross-sectional in the economy. They exist in all activity sectors, and are not restricted to small and medium businesses, even if this is the dominant form. Similarly, family businesses maintain an emotional tie with the place they originated from, where they started their activity in the first place, and they tend to contribute to local development, not only directly through the creation of jobs, but also through regional promotional initiatives. By the influence of the founder's values, the importance of family reputation and the concern in maintaining family leadership, these businesses tend to display equally a greater willingness towards social responsibility, translated in a sense of family duty in serving society (Jayantital, 2016; Botero, De Massias, Nordqvist, 2015; Liyz, 2008). Given their national and international relevance (Graves, Thomas 2008, 2004; Gallo, GarciaPont, 1996), three arguments are brought forward which support the diagnosis of the current reality of family businesses.

First of all, one of the greatest problems that businesses face in Portugal (and in Europe) is the lack of institutional visibility, where there are still no precise and updated official statistics about this sector of the economy. The European Commission (EC, 2009) indicates that family businesses represent more than $65 \%$ of the business fabric and 40 to $50 \%$ of employment in the European Union. In Portugal, those numbers are substantially higher, however, specific information about those companies is scarce. In Portugal, it is estimated that family businesses may represent between $70 \%$ to $80 \%$ of the national companies, taking up $50 \%$ of the workforce and contributing to $2 / 3$ of the GDP. Nonetheless, it is still difficult to give an accurate number of how many Small and Medium Enterprises may be family businesses, and if they are, we still need to ascertain their dynamics in the (potential) contribution they can make to the national and international markets. Consequently, the mapping of this dominant business typology in the Portuguese economic fabric and their characteristics/profiles, is essential as support to the future development of public policies aimed at the support of family businesses.

Secondly, it is important to emphasise the internal heterogeneity and the specific challenges that characterise this business typology. In effect, family businesses constitute the predominant basis of the entrepreneurial fabric of most countries, and the representativeness of this company form is therefore undeniable, notwithstanding the fact that the weight varies from economy to economy. At the European level (Botero, De Massias, Nordqvist, 2015), small and medium family businesses constitute a substantial part of the European companies and of the vigour of the European economy, representing $60 \%$ of that business sector. In Portugal, this reality seems more specific since, besides integrating big businesses, it is mainly the Small and Medium Enterprises, particularly the micro-companies (comprising up to 9 workers) that have greater relevance in the economy. Family businesses are distributed by different activity sectors, such as wholesale and retail trade, accommodation and catering industry, education, human health and social assistance, fishery sector, building industry, among others. In turn, under the same designation of "family business", two distinctive realities may be included in terms of dimension, professional degree, management and government, organisational structures, including, at times, complex subcontracting networks or outsourcing to boost emerging value-added niche markets, or to externalise production chain 
activities. In this context, we may include not only family businesses that survived to uphold the family "trade" but also, in the opposite direction, they include economic agents of significant importance quoted on the stock market, constituting large economic groups. They may include businesses with significant levels of innovation and professionalisation, however, the significant deficits are more meaningful concerning the digital economy and innovation in the industry framework 4.0 and of trade professionalisation (governance), managers and HR. On this last item, the lower attention and/or preparation of the family businesses for succession planning takes on a critical dimension for the sustainability of the family business (Costa, Negreiro, Negreiro, 2011; Habbershon, Williams, 2002, 1999; Gersick, Davis, Hampton, Lansberg, 1997). According to a recent study directed towards the importance of corporate succession in Portugal (AEP, 2011), $50 \%$ of family businesses are not transferred to the second generation, and only $20 \%$ reach the third generation, which explains, to a great extent, that only $11 \%$ of the surveyed companies have attributed great importance to the planning of their business succession. When we discuss this business reality, it is important to bear in mind that there is no consensual definition among the governmental entities, the economic agents and the different scientists devoted to this topic. Nonetheless, by family business we understand the company controlled by the family, in terms of appointing management positions, and some of its members participate and work in the company.

Thirdly, these family businesses adopt a certain invisibility/depreciation of their potential in the transformation of the pattern of industrial specialisation and innovation, and of transfer of technology and knowledge. Still unknown are the effects of the Family Businesses (FB) regarding: i) their economic contribution in the production chain of wealth creation and added value, especially as regards the intake of technology and knowledge transfer (mainly via start-ups and entrepreneurial initiatives linked to R\&D sectors and innovation), and also via accession to the digital economy; ii) the volume of employment created and consolidated over the cycle of economic activity, particularly absorbing skilled labour; iii) the capacity for innovation at the level of processes, materials and goods/services which, produced locally, has come to win over international and globalised markets; iv) the professionalisation and leadership models, taking into account their specificities, including at this stage the most critical factors of conflict management of family business and emotional intelligence; v) the capacity to organise into networks and partnerships, sharing the available resources via the use of collaborative online platform of different social and economic agents (from R\&D centres, universities, professional schools for clients and suppliers); vi) concerning the development potential of territorial cohesion for the ability to attract and set human resources locally, highlighting the role of this kind of businesses in terms of their long-run stability and the special bond they develop with local communities.

\section{Roadmap for family business: some empirical findings}

\subsection{Methodological notes}

An (online/ on-site) survey circumscribed to the North region of Portugal, was applied to a previously selected database from a systematic collection of companies that corresponded to the family business profile. From the universe of more than 41 thousand businesses that were part of the databank, a sampling plan followed, which was based on the representativeness of the distribution of family businesses per NUT III (North sub-regional divisions), and per dimension of the business defined by number of workers. For ease of reference of the collection process, only three groups of business were considered, according to the number of workers: smaller businesses (up to 10 workers), intermediate dimension businesses (from 10 to 49 workers) and larger-scale (with 50 or more workers). Bearing in mind our study goals, it was possible to ensure the constitution of a sample of 1148 family businesses, considered as robust in terms of representation of the target-universe, ensuring a trust level of $95 \%$, with a maximum error of $3 \%$ (cf. Table 1).

Table 1 - Distribution of the final sample by NUT III (North sub-regional divisions) and size

\begin{tabular}{|c|c|c|c|c|c|}
\hline \multirow[b]{2}{*}{ NUT III } & \multicolumn{4}{|c|}{ Size (number of workers) } & \multirow[b]{2}{*}{ Total } \\
\hline & $\begin{array}{l}\text { Micro } \\
\leq 3\end{array}$ & $\begin{array}{l}\text { Micro } \\
(4-9)\end{array}$ & $\begin{array}{l}\text { Small } \\
(10-49)\end{array}$ & $\begin{array}{l}\text { Medium and Large } \\
\text { Company } \\
(\geq 50)\end{array}$ & \\
\hline \multirow{2}{*}{ Alto Minho } & 10 & 28 & 20 & 9 & 67 \\
\hline & 14.9 & 41.8 & 29.9 & 3.4 & 5.8 \\
\hline
\end{tabular}




\begin{tabular}{|c|c|c|c|c|c|}
\hline \multirow{2}{*}{ Alto Tâmega } & 2 & 10 & 6 & 3 & 21 \\
\hline & 9.5 & 47.6 & 28.6 & 14.3 & 1.8 \\
\hline \multirow{2}{*}{ Área Metropolitana do Porto } & 200 & 146 & 142 & 55 & 543 \\
\hline & 36.8 & 26.9 & 26.2 & 10.1 & 47.3 \\
\hline \multirow{2}{*}{ Ave } & 25 & 40 & 45 & 28 & 138 \\
\hline & 18.1 & 29.0 & 32.6 & 20.3 & 12.0 \\
\hline \multirow{2}{*}{ Cávado } & 45 & 56 & 59 & 29 & 189 \\
\hline & 23.8 & 29.6 & 31.2 & 15.3 & 16.5 \\
\hline \multirow{2}{*}{ Douro } & 16 & 18 & 13 & 6 & 53 \\
\hline & 30.2 & 34.0 & 24.5 & 11.3 & 4.6 \\
\hline \multirow{2}{*}{ Tâmega e Sousa } & 25 & 28 & 34 & 23 & 110 \\
\hline & 22.7 & 25.5 & 30.9 & 20.9 & 9.6 \\
\hline \multirow{2}{*}{ Terras de Trás-os-Montes } & 3 & 14 & 8 & 2 & 27 \\
\hline & 11.1 & 51.9 & 29.6 & 7.4 & 2.4 \\
\hline \multirow{2}{*}{ Total } & 326 & 340 & 327 & 155 & 1148 \\
\hline & 28.4 & 29.6 & 28.5 & 13.5 & \\
\hline
\end{tabular}

Source: FB Survey

To administer the questionnaire, platform LimeSurvey was used (June and July 2017) and an on-site application of the questionnaires to the family businesses (October 2017 to February 2018), preceded by a pre-test.

The information gathered by the family businesses in the North region via the questionnaire was geared towards the most relevant dimensions and indicators, namely: i) company identification; ii) generic characterisation of the entrepreneurial activity; iii) family structure and governance; iv) Professionalisation of the business families; v) Socio-biographical characterisation of the survey respondent, who may have been the founder himself/herself or the family business CEO, knowledgeable of the family business itself.

\subsection{Profiles of family business}

Through the intersection of some indicators such as dimension and seniority of the participating family businesses of the study, the distinguishing characteristics are listed below. These are mainly located in the metropolitan area of Porto, which is separated by a considerable percentage differential from the following: Cávado, Ave and Tâmega, and Sousa regions (cf. Graph 1). 


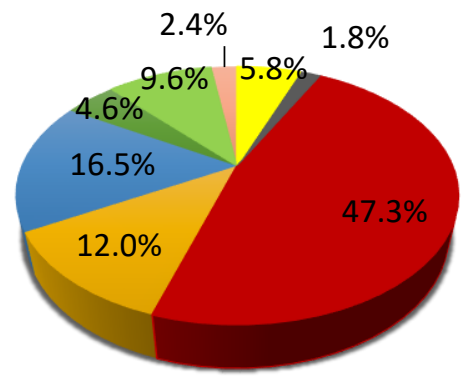

\author{
Alto Minho \\ - Alto Tâmega \\ - Área Metropolitana \\ do Porto \\ Ave \\ - Cávado \\ - Douro \\ - Tâmega e Sousa \\ - Trás-os-Montes
}

Graph 1 - Participant family businesses by NUT III (North sub-regional divisions)

\title{
Source: FB Survey
}

According to the three-circle model (Tagiuri, Davis, 1992, 1982), family businesses undergo an evolution cycle that goes from birth to the growth phase of both business and family all the way to their implosion. This coincides with the expansion of markets, products and services as well as with a tendentially more complex governance structure, due to the emergence of spouses and of the third generation, which fosters the emergence of family clusters. According to our results, more than half of participating businesses have up to 20 years of operation (51.8\%), although the 20 to 49 -year range boasts a highly significant percentage (41.3\%). Businesses with $50+$ years correspond to $6.7 \%$ of the sample, and only $0.3 \%$ declare to have been in operation for more than 100 years (cf. Graph 2).

We are dealing with family businesses in the phase of business and family growth, although many are already at a stage of consolidation and constitution of several family clusters. Issues pertaining to the professionalisation and growth of the business activity, on the one hand, and the constitution of households and their descendants, on the other, are the most critical challenges faced by these businesses. The most common legal form is that of limited company $(71 \%)$, followed by public limited company, with equal percentage, and sole proprietorship (10.5\%). As for the size of the participating family businesses, micro businesses predominate, with $58 \%$, followed by small businesses (between 10 and 49 workers), with $28.5 \%$. Businesses with $100+$ workers are also represented in the sample, and their relative weight $(6 \%)$ is significant, considering the low percentage of such businesses in the North (cf. Graph 3).

\section{$6.7 \% \quad 0.3 \% 10.9 \%$}

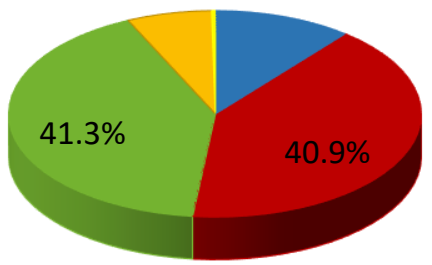

- 0 a 4 years

$\square 5$ a 19 years

20 a 50 years

$\square 51$ a 100 years

$101+$ years 
Graph 2 - Participating family businesses by seniority

Source: FB Survey

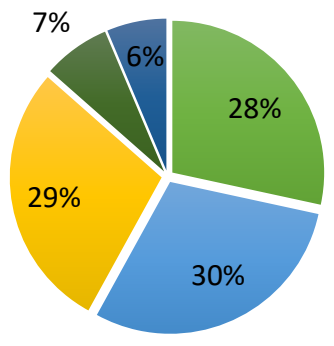

- Until 3 workers

- 4 - 9 workers

10 - 49 workers

- 50 -99 workers

100 + workers

Graph 3 - Participating family businesses by size (year of 2016 as reference)

\section{Source: FB Survey}

The sectors of wholesale and retail trade, manufacturing industry and consulting, scientific and technical activities are of particular importance, as well as accommodation and catering and the building sector (cf. Graph 4).

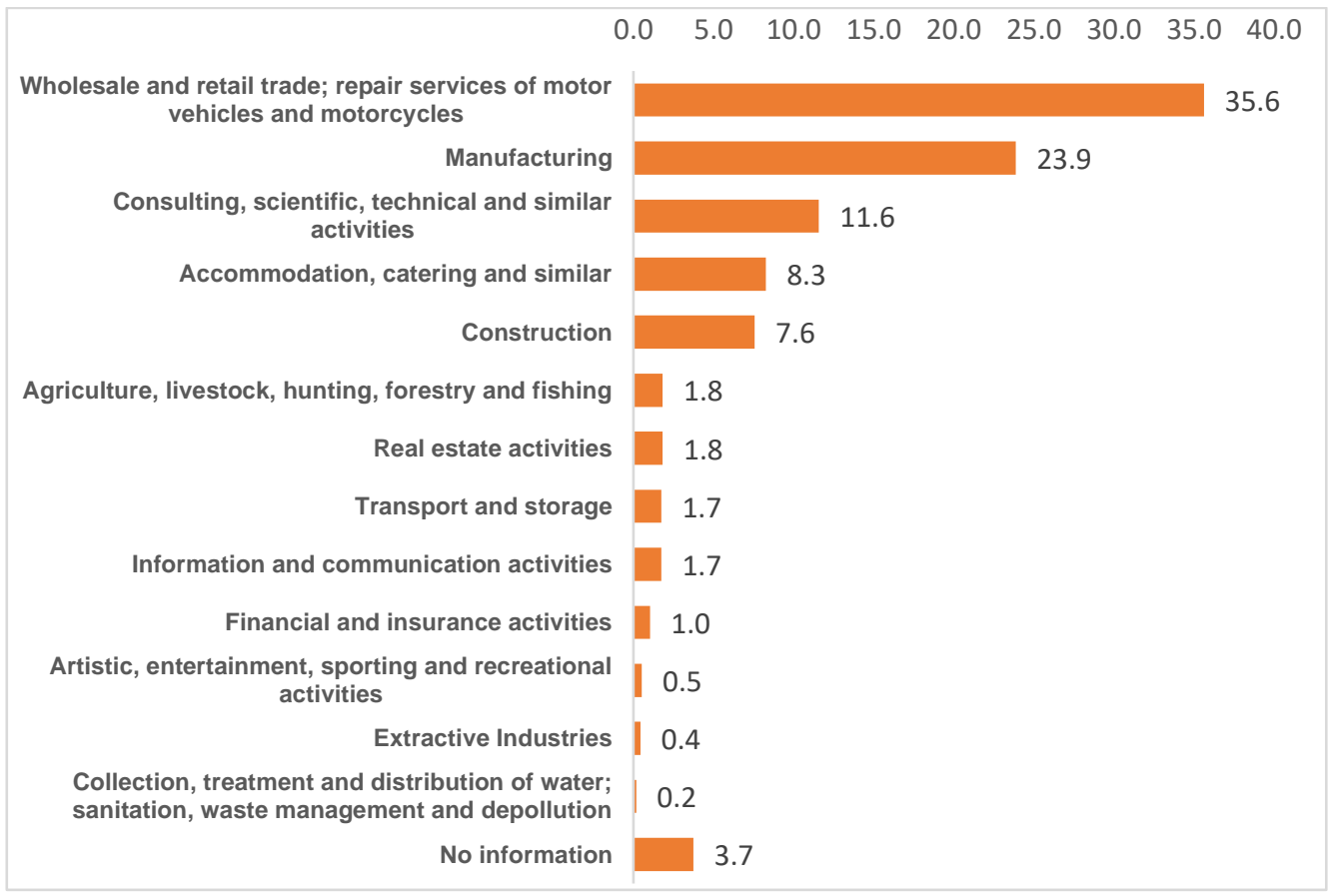

Graph 4 - Classification of economic activity of family business 


\section{Source: FB Survey}

The analysis of economic activity shows a greater number of family businesses $(40.2 \%)$ had a total turnover - which includes sales of products, goods and provision of services - below 250,000 euros. However, $30.7 \%$ surpassed one million euros and $12.4 \%$ exceeded five million euros (only $2.7 \%$ were over 25 million). A large majority (86.8\%) of micro businesses with up to three workers had a total turnover below 250,000 euros. As for micro businesses with four to nine workers, $48.2 \%$ did not reach 250,000 euros, $13.5 \%$ had a total turnover between 250,000 and 500,000 euros, and $7.1 \%$ exceeded 500,000 euros. The main share of total turnover of small businesses was between one and five million euros (42.8\%), with $11.9 \%$ going over five million euros. Lastly, in medium and large businesses the main share of total turnover was between five and 25 million euros (49\%), with $14.8 \%$ surpassing 25 million euros (cf. Graph 5).

Graph 5 - Total turnover of family businesses (on 31/12/2016)

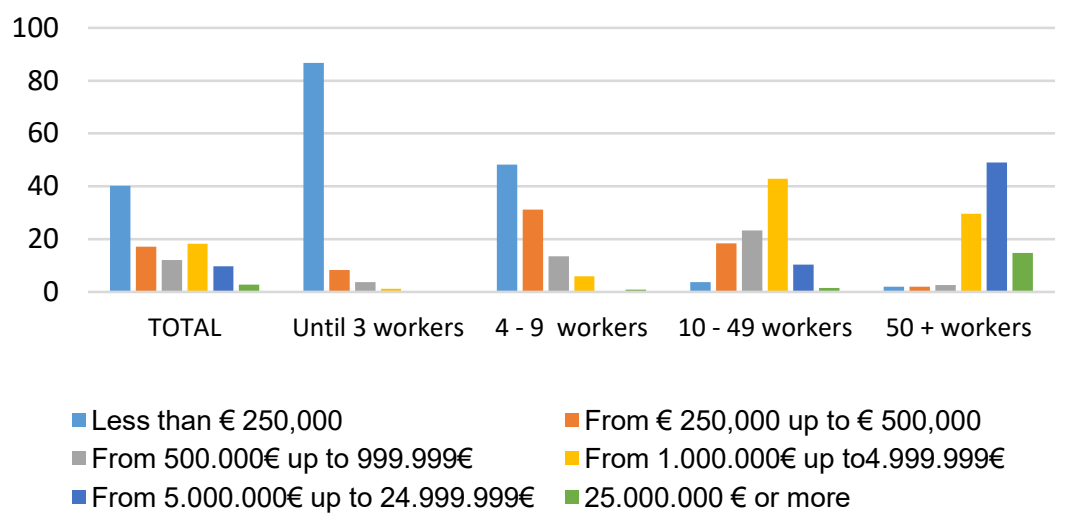

\section{Source: FB Survey}

As a rule, family businesses are characterised by low levels of risk propensity, opting for own funds and thus keeping their long-term levels of indebtedness at a minimum. This type of behavior also allows businesses to defend themselves against a possible loss of control. It should also be noted that many family businesses use their own funds because they are unable to access other forms of funding.

The results of the questionnaire given to family businesses show that self-funding (59.8\%) and banks (46.3\%) are the main funding sources of family businesses. However, $21.6 \%$ have to resort to family funds and $7.4 \%$ to the sale of assets. In the case of micro businesses, mostly those with up to three workers, $66.9 \%$ must use own funds, whereas small businesses mainly resort to banks $(71.0 \%$ and $62.4 \%$, respectively). The largest businesses have the least need to use family funds (7.1\%) (cf. Graph 6). There is also a tendency, even if it is not very pronounced, for more recent businesses to resort proportionally to self-funding and family funds, whereas businesses with more years of existence tend to rely on banks (cf. Graph 7).

Graph 6 - Main funding sources by size 


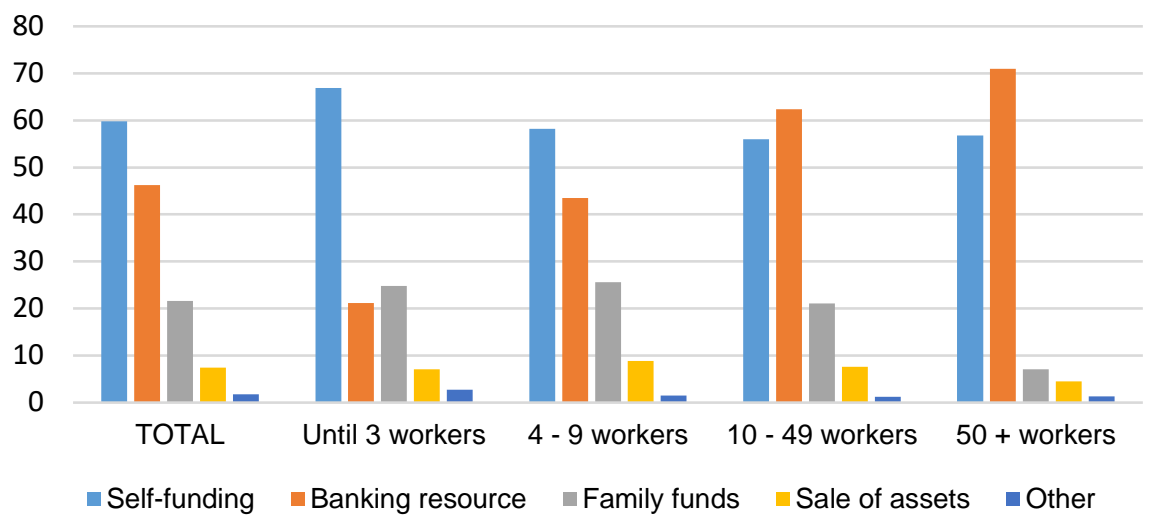

Source: FB Survey

Graph 7 - Main funding sources by seniority

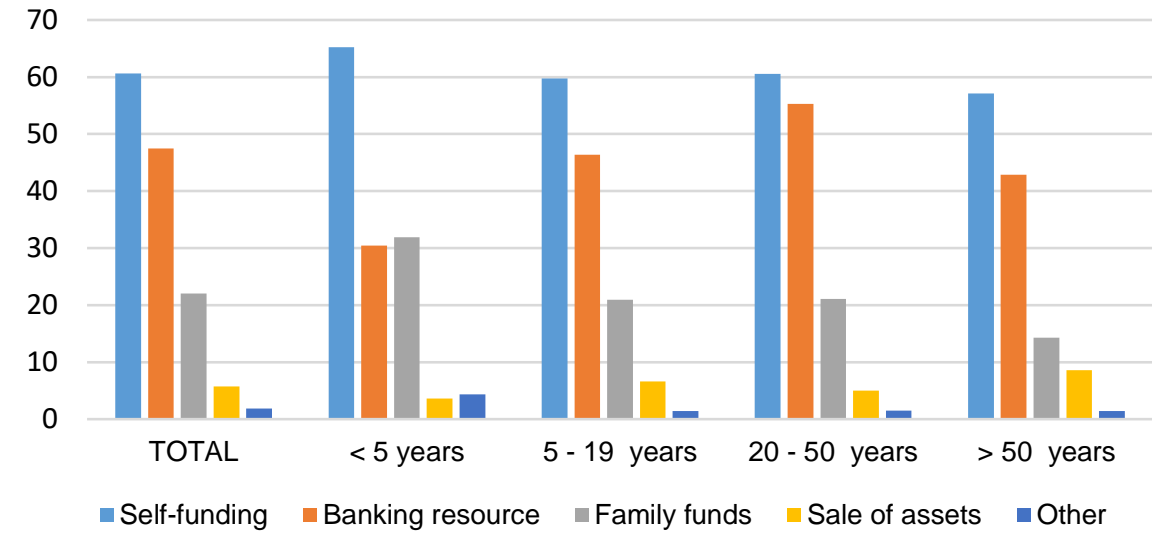

\section{Source: FB Survey}

It would appear that one of the specificities of family businesses, particularly small ones and recent ones, lies in the importance of family funds to support/implement a business or entrepreneurial endeavour, which could otherwise be unfeasible (they often serve as lenders of last resource). Nevertheless, while the family role can be crucial to the entrepreneurial endeavour and business growth, the management strategy is not always aligned with that of the family, which may raise obstacles to funding the business. For example, such options as going public (via capital market) or establishing other types of strategic partnerships (for instance, joint ventures) to elicit changes in the business may not be accepted by the family and/or property, limiting access to those means of funding.

In turn, self-funding could prove restrictive for the business, as it reduces its ability to invest and grow. But this problem becomes even more serious as the business absorbs more generations. This is because, on the one hand, some family members may withdraw from business management, demanding rewards in the form of higher dividends and, on the other hand, there is a steady increase of family members joining the business. Hence, there is inevitable pressure on the liquidity of the family business, which reduces its ability to self-fund.

The products and services of family businesses are intended for all kinds of market - the local/regional market (35.4\%), the national market $(29.2 \%)$ or the national market combined with the international market (35.5\%). However, the type of 
market towards which business are geared is mostly associated with business size. The larger businesses are simultaneously geared towards the national and international markets $(76.1 \%)$, whereas businesses with up to three workers are more geared towards the local/regional market (55.8\%). If should further be noted that $43.7 \%$ of small businesses extend into the international market (cf. Graph 8).

Graph 8 - Main market of products or services by business size

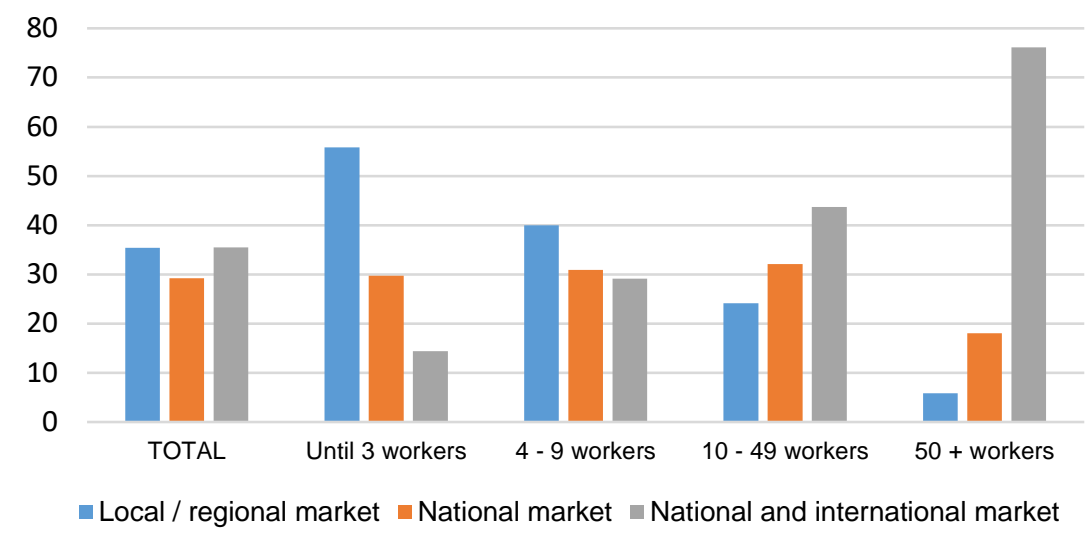

Source: FB Survey

\section{Key challenges faced by Portuguese family business}

Family businesses were asked to assess the importance of a set of indicators to the success of their businesses. Ten indicators were selected, and their importance was rated on a scale of $1=$ Not important to $5=$ Extremely important $(2=$ Not very important, $3=$ Important and $4=$ Very important) (cf. Graph 9).

On average, seven indicators were rated Very important (4), with particular relevance to the following: preparation and grooming of the successor before taking up any duties (4.13), separation between family interests and business interests (4.10) and existence of medium and long-term strategic planning (4.06). In contrast, the aspects rated the lowest by family businesses (i.e., 3 or lower) are: opening up capital to non-family members (1.99) and hiring external professional managers to run the business (2.67). Notwithstanding the fact that they display slightly different levels of importance, these indicators are not specific to a particular business size (cf. Graph 9 ). 


\section{Opening of share capital to non-family members}

Have external professional managers in the company

Maintaining family control in the business

Existence of an organizational structure with definition of roles and responsibilities

Prevalence of professional criteria in decision making on property, government and...

Communication between the generations of the family, anticipating business continuity

Keep the family informed of the business situation, including problems and decisions

Preparation and grooming of the successor

Existence of strategic planning (medium and long term)

Separation between family and business interests

\subsection{9}

\subsection{7}

3.61

3.90

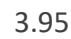

3.86

3.80

4.13

4.06

4.10

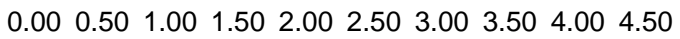

Graph 9 - Level of importance (average value) of requirements for the success of the family business

Source: FB Survey

If we sort this analysis by size and seniority of the business, the results are quite similar, which attests to the cross-cut of the three main challenges faced by family businesses: 1) preparation and grooming of the successor before taking on any duties, 2) separation between family and business interests, and 3) existence of strategic planning (medium and long term). Furthermore, in order to maintain power and control over the business in the hands of the family, there is a tendency to avoid opening up capital to non-family members and hiring external professional managers to run the business.

\section{Final remarks}

Family businesses are generically defined by the intrinsic involvement of family members in the management and administration boards. As such, they have interesting and unique features which set them apart from other businesses, highlighting their importance in market economies worldwide. It is acknowledged that family businesses have greater resilience and longevity when compared to other businesses, as they are characterized by the preservation of values and traditions by future generations. This helps forge a bond between the business and the family, ensuring that control over the business remains in the family.

In view of this reality, it becomes clear that the long-term strategic vision for family businesses has little interest in the possibility of opening to third parties (i.e., non-family members). Considering that business performance tends to be influenced by size and seniority: we observe that larger business with more years of existence not only have less need for self-funding and family funds, but they have a higher share of exports in total turnover.

Pursuing the effort to map the predominant business typology in the Portuguese economic sector and pinpointing its main trends and emerging profiles is key to support the future development of public policies aimed at providing support to family business.

\section{References}

[1] AEP (2011). Livro branco da sucessão empresarial. O desafio da sucessão empresarial em Portugal. APE. 
[2] Botero, I. C., Cruz, C., De Massis, A., \& Nordqvist, M. (2015). Family business research in the European context. European Journal of International Management, 9(2), 139-159. DOI: 10.1504/EJIM.2015.067858

[3] Costa, António N.; Negreira, F.; Negreira, J. (2011). 50 Perguntas Essenciais sobre Empresas Familiares. Porto, Vida Económica.

[4] European Commission (2009). Final report of the expert group. Overview of the family-business-relevant issues: research, networks, policy measures and existing studies. http://ec.europa.eu/DocsRoom /documents/10388

[5] Gallo, M. A. \& GarcíaPont, C. (1996). Important factors in family business internationalization. Family Business Review, 9 (1), 45-59.

[6] Gersick, Kelin, E.; Davis, John A.; Hampton, Marion M.; Lansberg, Ivan (1997). Generation to Generation. Life Cycles of the Family Business. Boston, Massachusetts, Harvard Business School Press.

[7] Graves, C. \& Thomas, J. (2004). Internationalisation of the family business: A longitudinal perspective. International Journal of Globalisation and Small Business, 1(1), 7-27

[8] Graves, C. \& Thomas, J. (2008). Determinants of the internationalization pathways of family firms: An examination of family influence. Family Business Review, 21 (2), 151-167.

[9] Habbershon, T. G. \& Pistrui, J. (2002). Enterprising families domain: Family-Influenced ownership groups in pursuit of transgenerational wealth. Family Business Review, 15(3), 223-237.

[10] Habbershon, T.G.; Williams, M.L. (1999). A Resource-Based Framework for Assessing the Strategic Advantage of Family Firms. Family Business Review, 12 (1), 1-26,

[11] IFERA (2003). Family businesses dominate. Family Business Review, 16(4), 235-240.

[12] Jayantilal, S. (2016). Game Theory and Family Firm Succession. Universidade de Extremadura. Tese de Doutoramento, http://dehesa.unex.es/xmlui/handle/10662/4117

[13] Litz, R. A. (2008). Two sides of a one-sided phenomenon: Conceptualizing the family business and business family as a Mobius Strip. Family Business Review, 21(3), 217-236.

[14] Tagiuri, R. e Davis, J. (1982). Bivalent attributes of the family business. Working Paper, Cambridge, Massachusetts, Harvard Business School (Reprinted 1996, Family Business Review, IX (2), 199-208)

[15] Tagiuri, R. e Davis, J. (1992). On the goals of successful family companies. Family Business Review, 5(1), 4362. 